\title{
Peran Guru dalam Pembentukan Karakter Religius Melalui Pendidikan Ramah Anak di Sekolah Dasar Negeri 2 Taringgul Tonggoh Kecamatan Wanayasa
}

\author{
Iis Siti Robe'ah \\ STAI DR. KH.EZ Muttaqien Purwakarta \\ iis.sitirobeah98@gmail.com \\ Siswanto \\ STAI DR. KH.EZ Muttaqien Purwakarta \\ onex.scout1990@gmail.com
}

DOI: https://DOI.org/10.52593/pdg.02.2.03

Naskah diterima: 07 Juni 2021, direvisi: 23 Juli 2021, disetujui: 28 Juli 2021

\begin{abstract}
The role of teachers in schools is very important in the planting and character building of students. One character that must be formed, which is the basis of the other character is religious. Child-friendly education in Islamic education is an effort made by parents and educators to educate students by creating an environment of compassion as the nature of protection in Islam. At SD Negeri 2 Taringgul Tonggoh kec. Wanayasa kab. Purwakarta is one of the child-friendly schools that implements child-friendly education. This study aims to (1) Describe the role of teachers as mentors in the formation of religious character of students through education in the perspective of Islamic education at SD Negerti 2 Taringgul Tonggoh kec. Wanayasa kab. Purwakarta (2) describe the role of teachers as an example in the formation of student character through child-friendly education in the perspective of Islamic education at SD Negeri 2 Taringgul Tonggoh Kec. Wanayasa Kab. Purwakarata, and describe external factors that influence the formation of religious character of low-grade students through child-friendly education at SD Negeri 2 Taringgul Tonggoh Kec. Wanayasa Kab. Purwakarata. This research was conducted using Qualitative method. The results of this study show that: the role of teachers as mentors of the religious character of students through childfriendly education in the perspective of Islamic education, namely teachers invite students to be active in conducting religious activities that can shape the character of the student itself, teachers always remind and advise students at all times not to commit violence, do good things taught by Islamic teachings, do bad things that are forbidden by Islamic teachings, and also always do worship that must be done. The role of teachers as an example in the formation of religious character of students through child-friendly education in the perspetif of Islamic education is by exampleing students through participating in habituations in schools or setting examples of good morals and good habits so that they can be exemplified by students.
\end{abstract}

Keyword: The Role of the Teacher, Religious Character, Child-Friendly Education 


\begin{abstract}
Abstrak
Peran guru di sekolah sangat penting dalam penanaman dan pembentukan karakter siswa. Salah satu karakter yang harus dibentuk, yang merupakan dasar dari karakter yang lain adalah religious. Pendidikan ramah anak dalam pendidikan Islam adalah upaya yang dilakukan oleh orang tua maupun pendidik untuk untuk mendidik siswa dengan menciptakan lingkungan yang penuh kasih sayang sebagai hakikat perlindungan dalam Islam. Di SD Negeri 2 Taringgul Tonggoh kec. Wanayasa kab. Purwakarta merupakan salah satu sekolah ramah anak yang menerapkan pendidikan ramah anak. Penelitian ini bertujuan untuk (1) Mendeskripsikan peran guru sebagai pembimbing dalam pembentukan karakter religious siswa melalui pendidikan dalam perspektif pendidikan Islam di SD Negerti 2 Taringgul Tonggoh kec. Wanayasa kab. Purwakarta (2) mendeskripsikan peran guru sebagai teladan dalam pembentukan karakter siswa melalui pendidikan ramah anak dalam perspektif pendidikan Islam di SD Negeri 2 Taringgul Tonggoh Kec. Wanayasa Kab. Purwakarata, dan mendeskripsikan faktor-faktor eksternal yang mempengaruhi pembentukan karakter religius siswa kelas rendah melalui pendidikan ramah anak di SD Negeri 2 Taringgul Tonggoh Kec. Wanayasa Kab. Purwakarata. Penelitian ini dilaksanakan dengan menggunakan metode Kualitatif. Hasil penelitian ini menunjukkan bahwa: peran guru sebagai pembimbing karakter religius siswa melalui pendidikan ramah anak dalam perspektif pendidikan Islam yaitu guru mengajak siswa untuk aktif dalam melaksnakan kegiatan-kegiatan keagamaan yang dapat membentuk karakter siswa itu sendiri, guru selalu mengingatkan dan menasihati siswa setiap saat agar tidak melakukan kekerasan, melakukan hal-hal baik yang diajarkan oleh ajaran Islam, menjuhi hal-hal buruk yang dilarang oleh ajaran Islam, dan juga selalu melakukan ibadah yang harus dilakukan. Peran guru sebagai teladan dalam pembentukan karakter religius siswa melalui pendidikan ramah anak dalam perspetif pendidikan Islam yaitu dengan cara memberi contoh kepada siswa melalui ikut dalam pembiasaan-pembiasaan yang ada di sekolah ataupun memberi contoh akhlak yang baik dan kebiasaan-kebiasaan baik sehingga dapat dicontoh oleh para siswa.
\end{abstract}

Kata Kunci : Peran Guru, Karakter Religius dan Pendidikan Ramah Anak

\title{
A. Pendahuluan
}

Di dunia pendidikan, guru adalah seorang pendidik, pengajar, pembimbing, pelatih, penasihat, korektor, organisator, motivator, fasilitator, pengelola kelas, mediator, model dan teladan bagi siswa. Seorang guru harus dapat menciptakan kondisi dan suasana belajar yang kondusif, yaitu suasana belajar yang menyenangkan, menarik, memberi rasa aman, mengarahkan siswa kepada jalan yang benar, memberikan ruang pada siswa untuk berfikir aktif, kreatif, dan inovatif dalam mengeksplorasi kemampuannya. 
Karakter yang baik merupakan hal yang diinginkan setiap orang tua bagi anak-anaknya. Seorang filsuf Yunani bernama Aristoteles mendefinisikan karakter yang baik sebagai kehidupan dengan melakukan Tindakan-tindakan yang benar sehubungan dengan diri sendiri dan orang lain. ${ }^{1}$ Menurut Imam Al-Ghozali, pendidikan merupakan proses memanusiakan manusia sejak masa kejadiannya sampai akhir hayatnya melalui berbagai ilmu pengetahuan yang disampaikan dalam bentuk pengajaran secara bertahap, dimana proses pengajaran itu menjadi tanggung jawab orang tua dan masyarakat menuju pendekatan diri kepada Allah Swt sehingga menjadi manusia yang sempurna. ${ }^{2}$

Konsep pendidikan ramah anak terlahir karena adanya UU No.23 Tahun 2002 tentang perlindungan anak sebagai implementasi dari Konvensi Hak Anak (KHA) di Indonesia. Konvensi Hak Anak (KHA) adalah konvensi Perserikatan Banga-Bangsa (PBB) yang melindungi hak-hak anak. Undang Undang Perlindungan Anak adalah salah satu bagian dari mengoprasionalkan Konvensi Hak Anak (KHA). UU Perlindungan Anak adalah suatu undang undang mengenai hak-hak anak yang menjelaskan secara rinci mengenai perlindungan anak. Perlindungan ini meliputi perlindungan terhadap kekerasan, ekspolitasi, diskriminasi, dan penelantaran. Salah satu kekuatan dari UU ini adalah adanya sangsi yang jelas dan tegas terhadap siapa saja yang melakukan pelanggaran terhadap hak anak. ${ }^{3}$

Dalam pendidikan Islam, pendidikan ramah anak tetap diterapkan, sebab dalam pendidikan Islam anak merupakan sejuta energi yang akan menguatkan ikatan cinta, ikatan asa, dan ikatan-ikatan lain. Sekolah sebagai tempat pendidikan dimana guru memiliki kekuatan untuk menanamkan nilai-nilai dan karakter pada anak. Namun, tidak banyak guru yang menyadari akan pentingnya peran dari seorang guru serta belum faham bagaimana guru tersebut dapat mengambil perannya dalam pembentukan karakter siswa yang amat sangat dibutuhkan paling dasar dalam kehidupan, yakni nilai-nilai karakter religious. Masih banyak siswa yang belum menerapkan kebiasaan-kebiasaan baik yang diajarkan oleh ajaran Islam dalam

\footnotetext{
${ }^{1}$ Khanza Az-Zahra, "Karakteristik Menurut Para Ahli”, kerasipan dosenpsikologi.com ( 2019)

${ }^{2}$ Guru Pendidikan, "Pengertian Pendidikan", Kerasipan gurupendidikan.com (2020)

${ }^{3}$ Nurdin Cahyadi, "Sinergikan Sekolah Ramah Anak SRA", disdik.purwakarta.go.id (2020)
} 
kehidupan sehari-hari, seperti masih banyak siswa yang berbicara kotor dengan temannya, makan dan minum dengan berdiri atau berjalan, dan siswa yang masih berbicara pada saat berdoa sebelum ataupun sesudah belajar. Itu merupakan bukti bahwa guru belum berhasil dalam peranannya untuk menerapkan nilai-nilai akhlak dan adab yang baik. Karna sebagaimana kita tahu, ajaran yang diajarkan oleh agama Islam merupakan ajaran pokok yang harus diterapkan kepada anak. Dan sekolah merupakan pemegang peranan yang sangat penting untuk membantu siswa dalam memahami mana yang baik dan mana yang kurang baik untuk dirinya maupun untuk orang lain.

Di SD Negeri 2 Taringgul Tonggoh kec. Wanayasa kab. Purwakarta adalah salah satu sekolah dasar yang menerapkan pendidikan ramah dan mengedepankan nilai nilai religious dalam pembentukan karakter siswa. Hal ini merupakan salah satu implementasi program sekolah ramah anak yang diterapkan di sekolah tersebut. Siswa di sekolah ini sangat aktif, baik dalam kelas maupun luar kelas. Jumlah siswa yang cukup banyak, dengan jumlah perkelas 25-30 siswa. Banyaknya factor yang mempengaruhi pergaulan siswa di masyarakat, sangatlah berpengaruh pada perilaku siswa.

Berdasarkan uraian di atas, peneliti tertarik untuk mengadakan penelitian dengan judul "Peran Guru dalam Pembentukan Karakter Religius Siswa Melalui Pendidikan Ramah Anak di SD Negeri 2 Taringgul Tonggoh Kec. Wanayasa”.

\section{B. Teori / Konsep}

\section{Peran Guru}

Peran guru merupakan suatu tugas pokok yang dilakukan oleh seorang guru dalam kegiatan pembelajaran. Peran guru sangan menentukan keberhasilan siswa, karena guru lah yang langsung berinteraksi dengan siswa. Prey Katz dalam Sardiman A.M, menggambarkan peranan guru sebagai komunikator, sahabat yang dapat memberikan nasihat-nasihat, motivator sebagai pemberi inspirasi dan dorongan, pembimbing dalam pengembangan sikap dan tingkah laku serta nilai-nilai, orang yang menguasai bahan yang diajarkan. Proses pembelajaran akan berhasil manakala siswa mempunyai motivasi dalam belajar. Motivasi dapat diartikan sebagai tujuan atau pendorong, dengan tujuan 
sebenarnya menjadi penggerak utama bagi seseorang dalam berupaya dalam mendapatkan atau mencapai apa yang diinginkannya baik itu secara positif maupun negative. Seperti yang dikatakan oleh Suhardi. Bahwa motivasi terbagi menjadi 2(dua) jenis yaitu motivasi intrinsic dan motivasi ekstrensik. Motivasi intrsinsik adalah motivasi yang datangnya dari dalam diri seseorang. Motivasi ekstrinsik adalah kebalikannya dari motivasi intrinsic, yaitu motivasi yang muncul karena pengaruh dari lingkungan luar. Untuk itu, peran seorang guru sangatlah penting bagi perkembangan siswa, yang mana dibutuhkan seorang motivator guna mendorong kemajuan siswa, sehingga terciptanya rasa semangat untuk belajar dalam diri siswa. ${ }^{4}$

\section{Karakter Religius}

a. Karakter

Karakter merupakan watak/tabiat/kepribadian/sifat-sifat berdasarkan nilai-nilai yang diyakini dan melekat kuat dalam diri seseorang yang mendasari tindakan-tindakan yang dilakukan. Watak tersebut bersifat tetap sehingga menjadi pembeda anatara seseorang dengan lainnya. Hal ini sejalan dengan pendapat Gunawan bahwa karakter adalah keadaan asli yang ada dalam individu seseorang yang membedakan anatara dirinya dengan orang lain. Menurut Lickona karakter terbentuk dari tiga macam bagian yang saling berkaitan, yaitu pengetahuan moral (mantifak), perasaan moral (sosiofak) dan perbuatan moral (artifak).

b. Karakter Religius

Mujtahidin mengungkapkan karakter religious merupakan bentuk aktualisasi dari sikap dan perilaku seseorang yang mencerminkan kepercayaan dan keyakinan terhadap Tuhan YME yang ditunjukan melalui kepatuhan terhadap ajaran agamanya, tidak ingkar, dan taat menjalankan perintah dan menghindari larangan agama. ${ }^{5}$

\footnotetext{
${ }^{4}$ Sartika, "Peran Guru Dalam Memotivasi Siswa Yang Kesulitan Belajar Pada Pembelajaran PKN Di Kelas VII SMP Negeri 6 Palu", EDU CIVIC, Vol 6, No 02 (2018), 96.

${ }^{5}$ Lissetiyo Ningrum (dkk), "Pengembangan Karakter Religius Peserta Didik Melalui Pembelajaran Kimia Materi Hidrokarbon SMK”, dalam Jurnal Inovasi Pendidikan Kimia, Vol 14, No 1 (2020). 


\section{Pendidikan Ramah Anak}

Konsep pendidikan ramah anak terlahir karena adanya UU No.23 Tahun 2002 tentang perlindungan anak sebagai implementasi dari Konvensi Hak Anak (KHA) di Indonesia. Konvensi Hak Anak (KHA) adalah konvensi Perserikatan Bangsa-Bangsa (PBB) yang melindungi hak-hak anak. Undang-undang perlindungan anak adalah salah satu bagian dari mengoprasionalkan Konvensi Hak Anak (KHA) ${ }^{6}$. Sekolah ramah anak bukanlah membangun sekolah baru, namun mengkondisikan sebuah sekolah menjadi nyaman bagi anak serta memastikan sekolah memenuhi hak anak dan melindunginya, serta menjadikan sekolah sebagai rumah kedua bagi anak setelah rumahnya sendiri. Dengan demikian diharapkan sekolah mampu melahirkan generasi penerus yang berkepribadian ramah, sopan, santun, berkepribadian jujur dan lainnya. Menurut Kristanto, sekolah ramah anak adalah sebuah konsep sekola yang terbuka, berusaha mengaplikasikan pembelajaran yang memperhatikan perkembangan psikologi siswanya. Mengembangkan kebiasaan belajara sesuai dengan kondisi alami dan kejiwaan anak. ${ }^{7}$

\section{Metode Penelitian (Kualitatif)}

\section{Teknik Observasi}

Teknik Observasi menurut Nasution yang dikutip oleh Sugiyono, menyatakan bahwa observasi adalah dasar semua ilmu pengetahuan. Para ilmuwan hanya dapat bekerja berdasarkan data, yaitu fakta mengenai dnia kenyataan yang diperoleh melalui observasi. Pengamatan atau observasi diklasifikasikan atas pengamatan melalui cara berperan serta dan yang tidak berperan serta. Pada pengamatan tanpa peran sertaa, pengamat hanya melakukan satu fungsi, yaitu mengadakan pengamatan. Pengamat berperan serta melakukan dua peranan sekaligus, yaitu sebagai pengamat dan sekaligus menjadi anggota resmi dari kelompok yang diamatinya pada penelitian.

\footnotetext{
${ }^{6}$ Nurdin Cahyadi, "Sinergikan Sekolah Ramah Anak SRA", disdik.purwakarta.go.id (2020)

${ }^{7}$ Ika Candra Sayekti (dkk), "Muatan Pendidikan Ramah Anak Dalam Konsep Sekolah Alam”, dalam Jurna Profesi Pendidikan Dasar, Vol 5, No 1 (2018)

100 | Paedagogie: P-ISSN: 2337-6848, E-ISSN : 2723-5971
} 
Observasi partisipatif merupakan seperangkat strategi dalam penelitian yang tujuannya adalah untuk mendapatkan data yang lengkap. Hal ini dilakukan dengan mengembagkan keakraban yang dekat dan mendalam dengan satu kelompok orang di lingkungan alamiah mereka. Dalam penelitan ini, peneliti menetapkan sejumlah tujuan dan memenpatkan dirinya sebagai bagian dari objek yang sedang ditelitinya.

\section{Teknik Analisis Data}

Analisis data adalah proses mencari dan Menyusun secara sistematis data yang diperoleh dari hasil wawancara, catatan lapangan, dan dokumentasi dengan cara mengorganisasikan data ke dalam kategori, menjabarkan ke dalam unitunit, melakukan sintesa, Menyusun ke dalam pola, memilih mana yang penting dan yang akan dipelajari serta membuat kesimpulan sehingga mudah dipahami oleh diri sendiri maupun orang lain.

Penyajian Data (Data Display) setelah data direduksi, maka Langkah selanjutnya adalah mendisplay data. Pada penelitian kualitatif, penyajian data bisa dilakukan dalam bentuk uraian singkat, baga, hubungan antar kategori, flowchart dan sejenisnya. Akan tetapi, yang sering digunakan dalam penelitian kualitatif adalah teks yang bersifat naratif. ${ }^{8}$

\section{Hasil Penelitian dan Pembahasan}

\section{Hasil Penelitian}

a. SD Negri 2 Taringgul Tonggoh

SD Negeri 2 Taringgul Tonggoh merupakan sekolah yang berdiri pada tahun 1978, terletak di Jalan Giri Tirta Kahuripan Rt 012/004 Desa Taringgul Tonggoh Kecamatan Wanayasa Kabupaten Purwakarta. SD Negeri 2 Taringgul Tonggoh ini menerapkan system pendidikan ramah anak dengan mengutamakan karakter religious siswa. Berdasarkan pemaparan dari kepala SD Negeri 2 Taringgul Tonggoh yaitu Hj Cucu Sumiati,S.Pd, bahwa beliau menginginkan anak anak yang sekolah di SD Negeri 2 Taringgul Tonggoh bisa belajar dengan nyaman, aman, kondusif sehingga siswa memiliki pola fikir yang aktif, kreatif,

\footnotetext{
${ }^{8}$ Dosen Pendidikan 3, “ Teknik Pengumpulan Data”, diarsipkan dari dosenpendidikan.co.id, (2020). Paedagogie: P-ISSN: 2337-6848, E-ISSN : 2723-5971 | 101
} 
dan inovatif dalam mengeksplorasi dan mengelaborasi kemampuannya sesuai dengan bidang dan lingkungannya. Namun tidak hanya itu, menurut beliau yang paling penting adalah akhlak dan adab. Sebagaimana kita tahu bahwa akhlak merupakan pondasi utama dan lebih tinggi daripada ilmu. Untuk itu, di SD Negeri 2 Taringgul Tonggoh mengadakan kegiatan-kegiatan yang berkaitan dengan keagamaan, seperti pembiasaan di pagi hari, ekstrakulikuler berbasis Islam, dan lain-lain. Namun untuk membentuk itu semua diperlukan pembimbing yang handal, tidak lain dan tidak bukan adalah orang tua dan guru. ${ }^{9}$ b. Peran Seorang Guru Dalam Proses Pembentukan Karakter Religius

Berdasarkan hasil wawancara dengan kepala sekolah dan guru-guru SD Negeri 2 Taringgul Tonggoh, bahwa peran seorang guru dalam membentuk karakter siswa sangat penting dan sangat dibutuhkan. Kebanyakan seorang anak cenderung kurang mematuhi perintah orang tua itu sendiri, dalam artian kurang adanya responsife terhadap apa yang diperintahkan orang tua, karna memang kebanyakan rasa sayang orang tua itu sendiri menjadi penghalang bagi penegasan terhadap anak. Bahkan banyak sekali orang tua yang memasrahkan anaknya kepada guru, karena jika di rumah anak banyak mengabaikan apa yang orang tua perintahkan atau tidak mendengarkan apa yang orang tua sampaikan. Sedangkan di sekolah, anak lebih patuh terhadap apa yang diperintahkan oleh guru, karena di sekolah ada sebuah nilai yang dikejar oleh anak.

Seorang guru harus peduli terhadap kebutuhan anak (ramah anak), ketika anak sudah terbentuk akan kebutuhannya, maka secara tidak langsung religious anak akan terperhatikan, karena kebutuhan yang paling anak butuhkan adalah akhlaknya, prilakunya, dan adabnya. Dan itu merupakan esensi dari tujuan pendidikan ramah anak yang seseungguhnya, yakni memenuhi kebutuhan anak, baik fisik maupun psikis. Namun kebanyakan yang anak butuhkan adalah kebutuhuan psikis, seperti mentalnya, perkembangan jiwanya, bakat dan minatnya, dan lain lain.

Seorang guru (khususnya guru agama) harus bisa berperan banyak dalam pembentukan karakter anak, seperti:

\footnotetext{
${ }^{9}$ Ibu Cucu Sumiati,S.Pd Kepala SD Negeri 2 Taringgul Tonggoh. Wawancara. 27 Januari 2021 102 | Paedagogie: P-ISSN: 2337-6848, E-ISSN : 2723-5971
} 
- Mengadakan kegiatan kegiatan keagamaan, seperti:

$\checkmark$ Shalat Dhuha

$\checkmark$ Dibiasakan untuk sedekah

$\checkmark$ Membaca surat Yaasin di hari Jum'at, dan lain-lain

- Peringatan peringatan hari besar Islam

- Sebelum belajar anak diingatkan selalu berdo'a atau membaca surat-surat pendek

- Membiasakan untuk menjaga kebersihan

- Mengajak siswa/siswi untuk senantiasa membaca Al-Qur'an dan memahaminya, dan lain-lain

Tidaklah cukup jika hanya mengandalkan teori suri tauladan untuk pembentukan karakter pada anak, melainkan harus ada peran yang nyata dimana guru mengikutsertakan siswa dalam peran tersebut. Siswa lebih aktif dalam melaksanakan kegiatan kegiatan yang dapat membentuk karakter pada dirinya sendiri, seperti yang diatas. Karna untuk menciptakan sebuah karakter, diperlukan sebuah kebiasaan. Sesuatu yang berat akan terasa ringan jika sudah biasa dilakukan. Anak bisa karena terbiasa, lalu disana terbentuk siswa yang berkarakter religious. ${ }^{10}$

\section{Analisis dan Pembahasan}

Seorang guru memiliki berbagai peran di dunia pendidikan. Salah satunya yaitu peran guru sebagai pembimbing. Guru sebagai seorang pembimbing dapat diibaratkan sebagai pembimbing perjalanan yang berdasarkan pengetahuan dan pengalamannya dan mampu bertanggung jawab atas kelancaran perjalanan itu. Istilah perjalanan dalam hal ini tidak hanya menyangkut fisik, tetapi juga perjalanan mental, emosional, kreatifitas, moral dan spiritual yang lebih baik. Sebagai pembimbing perjalanan, guru memerlukan kompetensi yang tinggi untuk melaksanakan empat hal berikut:

\footnotetext{
${ }^{10}$ Bapak Iyan Sudiyana,S.Pd Guru SD Negeri 2 Taringgul Tonggoh. Wawancara. 27 Januari 2021 Paedagogie: P-ISSN: 2337-6848, E-ISSN : 2723-5971 | 103
} 
1. Guru harus merencanakan tujuan dan mengidentifikasi kompetensi yang hendak dicapai.

2. Guru harus melihat keterlibatan peserta didik dalam pembelajaran dan yang paling penting bahwa peserta didik melaksanakan kegiatan belajar itu tidak hanya secara jasmaniah, tetapi mereka harus terlibat secara psikologis.

3. Guru harus memaknai kegiatan belajar.

4. Guru harus melaksanakan penelitian. ${ }^{11}$

SD Negeri Taringgul Tonggoh kec. Wanayasa merupakan salah satu Sekolah Ramah Anak yang menerapkan pendidikan ramah anak sudah tidak melakukan kekerasan fisik dan diskrimnasi terhadap siswa. Meskipun dalam teori Sekolah Ramah Anak yang seharusnya sudah tidak ada diskriminasi dan juga kekerasan fisik dan psikis, akan tetapi pada kenyataanya di lapangan, kekerasan psikis yang dilakukan oleh guru pada siswa masih ada. Kekerasan psikis tersebut dilakukan guru pada saat siswa melakukan kesalahan, maka siswa tersebut dimarahi oleh guru. Hal tersebut tidak mudah dihindari oleh guru, karena menurut beberapa guru, dengan memarahi siswa diharapkan mampu memberikan efek jera terhadap siswa agar menadi individu yang lebih baik lagi dan disiplin.

Proses untuk pembentukan karakter religious siswa, guru hendaknya memperkuat dengan mengunakan pemahaman, pembiasaan, dan keteladanan. Apabila hanya dengan pemahaman dan ujaran saja tanpa pembiasaan, maka siswa hanya mengetahui teorinya tanpa adanya tindakan yang dilakukan dan apabila guru hanya teori tanpa adanya tindakan yang dilakukan dan apabila guru hanya teori tanpa adanya tindakan atau praktik yang dilakukan oleh guru dengan berperan langsung dan memberi contoh, maka tindakan tersebut juga tidak akan berjalan dengan baik. Keteladanan guru sangat diperlukan karena guru menjadi contoh atau teladan bagi siswa-siswanya. Apabila tingkah laku guru baik maka siswa juga akan mengikuti tingkah laku guru yang baik, begitupula dengan hal sebaliknya. Hal tersebut dikarenakan salah satu proses

\footnotetext{
${ }^{11}$ Ibu Sri Lestari,S.Pd Guru SD Negeri 2 Taringgul Tonggoh. Wawancara. 27 Januari 2021 104 | Paedagogie: P-ISSN: 2337-6848, E-ISSN : 2723-5971
} 
pembentukan karakter religious siswa adalah dengan cara guru memberikan contoh maka siswa akan mengikutinya. Contohnya pada saat berdoa diawal dan diakhir pembelajaran, guru juga ikut berdoa bersama siswa, kemudian pada saat salat berjamaah guru juga ikut melaksanakan salat berjamaah bersama siswa serta guru juga memberi contoh dengan berkata baik agar siswa juga mengikuti guru dengan selalu berkata baik.

Perilaku menyimpang pada siswa di SD Negeri 2 Taringgul Tonggoh kec. Wanayasa rata-rata sama. Perilaku tersebut yaitu ada siswa yang berdo'a tidak sungguh-sungguh atau masih bermain dan mengobrol Bersama teman, berkata kotor dan membully kekurangan antar sesame teman. Maka dari itu, guru sebagai pembimbing disini sangat dibutuhkan agar siswa mengetahui dan menerapkan perilaku yang baik. Sebagai pembimbing, apabila ada perilaku yang menyimpang pada siswa, maka guru kelas akan menasihati, mengingatkan, dan membimbing siswa agar tidak mengulangi perilaku yang tidak bai tersebut. Selain itu, sebagai guru sekolah dasar, maka setiap guru memiliki tanggung jawab sebagai guru bimbingan konseling untuk siswa. Kegiatan bimbingan konseling ini dilakukan pada setiap kegiatan belajar mengajar berlangsung.

\section{E. Kesimpulan}

Berdasarkan pada anilisis data diatas, dapat disimpulkan bahwa dalam pembentukan karakter religious siswa di SD Negeri 2 Taringgul Tonggoh, peran guru sangatlah penting. Yakni Pertama, guru berperan sebagai pengingat, penasihat dan pembimbing siswa agar tidak melakukan kekerasan fisik terhadap temantemannya di kelas, kegiatan tersebut disampaikan oleh guru diawal kegiatan secara berulang-ulang di kelas didepan siswa. Jika terjadi kekerasan atau bullying, guru memanggil siswa yang terlibat dalam kejadian tersebut, lalu membimbing melalui kegiatan bimbingan konseling. Sehinggat tercipta kelas untuk belajar yang nyaman, aman dan kondusif.

Kedua, Guru mengarahkan minat dan bakat siswa sesuai dengan kemampuannya, sehingga potensi-potensi yang ada dalam diri siswa dapat digali 
dan dikembangkan. Guru mengingatkan dan memberitahu dengan kasih sayang mengenai ibadah yang harus dijalankan oleh siswa, baik yang sunah maupun yang wajib. Seperti shalat 5 waktu, menjenguk apabila ada siswa yang sakit, berkata baik dan santun, adab Ketika hendak belajar, mengikutsertakan siswa dalam Peringatan Hari Besar Islam (PHBI), dan lain-lain. Guru mencontohkan teladan dan akhlak yang baik sehingga dapat dicontoh dan ditiru oleh siswa. Sehingga terciptanya generasi muda yang aktif, kreatif, inovatif dalam mengelaborasikan serta mengembangkan bakatnya dengan dibekali akhlak dan adab yang mulia sehingga dapat bermanfaat bagi agama, nusa dan bangsa.

\section{DAFTAR PUSTAKA}

Rohmawati, Nuri. Hangestiningsih, Endang. 2019. Kajian Program Ramah Anak n.

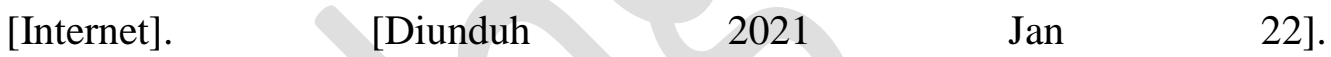
https://scholar.google.com/scholar?hl=id\&as_sdt=0\%2C5\&q=artikel+pendidikan+ra mah+anak\&btnG=

Nurrofi'ah, Siti. 2013. Implementasi Pendidikan Ramah Anak dalam Pembentukan Karakter Siswa Kelas Rendah SD Muhammadiyah Program Khusus Kota Barat Tahun Pelajaran 2013/2014. [Internet].[Diunduh 2021 Jan 23]. https://scholar.google.com/scholar?hl=id\&as sdt=0\%2C5\&q=artikel+sugiyono+pend idikan+ramah+anak\&btnG=

Rahardja, Untung. Dkk. Otomatisasi Role Online System Ticketing Raharja (Rooster) dalam Mendukung Pelayanan Offline Iduhelp! Pada Perguruan Tinggi. [Internet].[Diunduh 2021 Jan 23]. https://ilearning.me/jurnal-5/kerangka-jurnal/

Sugiono, Nanang. 2017. Nilai-Nilai Pendidikan Karakter Dalam Buku KebiasaanKebiasaan Inspiratif K.H Ahmad Dahlan Dan K.H Hasyim Asyari Karya M.Sanusi. [Internet]. [Diunduh 2021 Jan 24]. http://erepository.perpus.iainsalatiga.ac.id/1113/

Pendidikan 3, Dosen. 2020. Teknik Pengumpulan Data. [Internet]. [Diunduh 2021 Jan 24]. https://www.dosenpendidikan.co.id/teknik-pengumpulan-data/

Savitra, Khanza. 2019. 15 Karakteristik Menurut Para Ahli. [Internet]. [Diunduh 2021 Jan

https://dosenpsikologicom.cdn.ampproject.org/v/s/dosenpsikologi.com/pengert

106 | Paedagogie: P-ISSN: 2337-6848, E-ISSN : 2723-5971 
iankaraktermenurutparaahli/amp?amp_js_v=a6\&amp_gsa=1\&usqp=mq331A QHKAFQArABIA\%3D\%3D\#aoh=16114533580661\&referrer=https\%3A\%2F \%2Fwww.google.com\&amp_tf=Dari\%20\%251\%24s\&ampshare=https\%3A\% 2F\%2Fdosenpsikologi.com\%2Fpengertian-karakter-menurut-para-ahli

Pendidikan, Guru. 2020. Pengertian Pendidikan. [Internet]. [Diunduh 2021 Jan 25]. https://www.gurupendidikan.co.id/pengertian-pendidikan/

Misnatun, Misnatun. 2016. Pola Pendidikan Karakter Anak Melaui Pendidikan Ramah Anak Dalam Perspektif Pendidikan Islam. [Internet]. [Diunduh 2021 Jan 27]. http://garuda.ristekbrin.go.id/documents/detail/641680 